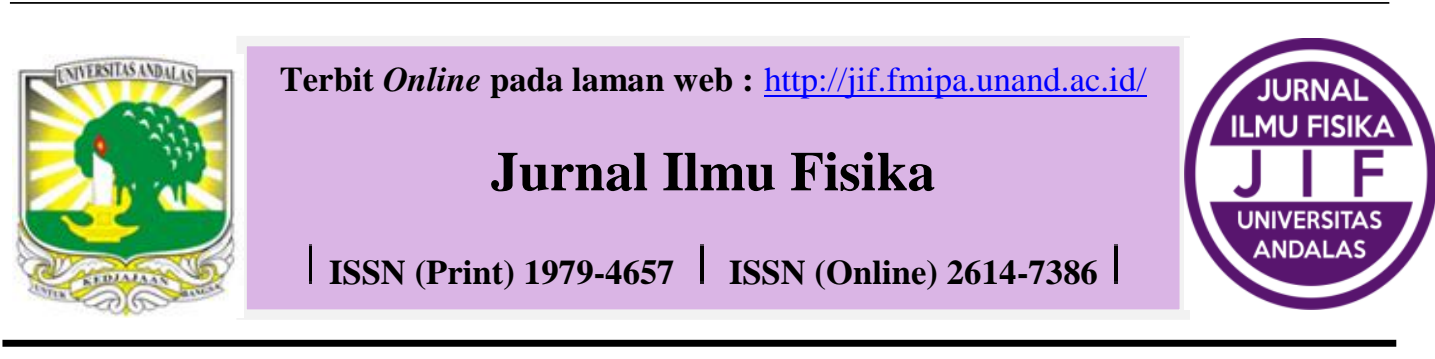

\title{
KARAKTERISTIK LINDI DAN AIR PERMUKAAN DI TEMPAT PEMBUANGAN AKHIR SAMPAH SUNGAI ANDOK KOTA PADANG PANJANG
}

\author{
Yonira Mike Vindi Marta*, Afdal \\ Jurusan Fisika, FMIPA, Universitas Andalas, Limau Manis, Padang, 25163 \\ *Korespondensi ke: yoniramike@ gmail.com
}

( Diterima:21 Desember 2018; Direvisi: 20 Februari 2019; Diterbitkan: 01 Maret 2019)

\begin{abstract}
ABSTRAK
Telah dilakukan penelitian untuk mengetahui karakteristik lindi dan air permukaan di tempat pembuangan akhir sampah, Sungai Andok, Kota Padang Panjang. Pengambilan sampel dilakukan pada 9 titik lokasi. Karakteristik lindi dan air permukaan ditentukan berdasarkan beberapa parameter yaitu Total Dissolved Solid (TDS), konduktivitas listrik, $\mathrm{pH}$, temperatur, dan kandungan logam berat $\mathrm{Fe}, \mathrm{Cu}, \mathrm{Pb}$, dan $\mathrm{Zn}$. Secara umum lindi di sekitar TPA Sungai Andok tidak mengalami pencemaran tinggi. Hal ini terlihat dari nilai rata-rata TDS $(1066,7 \mathrm{mg} / \mathrm{l})$, konduktivitas listrik $(1016,7 \mu \mathrm{m} / \mathrm{cm})$, dan temperatur $\left(24,96{ }^{\circ} \mathrm{C}\right)$ dan konsentrasi logam berat $\mathrm{Cu}$, $\mathrm{Fe}$, dan $\mathrm{Zn}$ yang tidak melebihi standar baku mutu berdasarkan PERMEN LH Nomor 5 Tahun 2014. Air sungai yang berada dekat TPA Sungai Andok belum tercemar dimana nilai hampir semua parameter yang diukur masih di bawah baku mutu berdasarkan PP Nomor 82 Tahun 2001. Tetapi, lindi dari TPA diduga mempengaruhi air sungai Andok dimana nilai semua parameter pada sampel air pada bagian sungai setelah melewati TPA lebih tinggi daripada nilai sebelum melewati TPA. Sampel air pada sumur pantau memiliki nilai rata-rata konduktivitas listrik sebesar 300,5 $\mu \mathrm{m} / \mathrm{cm}$, temperatur sebesar $24,67{ }^{\circ} \mathrm{C}, \mathrm{pH}$ adalah 6,6 dan TDS sebesar $960 \mathrm{mg} / \mathrm{l}$. Nilai-nilai tersebut hampir sama dengan nilai pada sampel lindi. Konsentrasi logam berat yang didapat juga melebihi baku mutu, dan lebih tinggi daripada sampel lainnya. Berdasarkan hasil ini diperkirakan lindi telah merembes ke dalam lapisan tanah.
\end{abstract}

Kata kunci : TPA Sungai Andok, lindi, konduktivitas listrik, TDS, danpH. 


\begin{abstract}
The characterstics of leachate and surface water at Sungai Andok landfill (TPA) in Padang Panjang Town has been investigated. Samples were collected at 9 points. The characteristics of leachate and surface water have been determined by several parameters i.e., Total Dissolve Solid $(T D S)$, electric conductivity, $\mathrm{pH}$, temperature and the content of heavy metal such as $\mathrm{Fe}, \mathrm{Cu}, \mathrm{Pb}$ and $\mathrm{Zn}$. In general, leachate around the Andok River landfill is not highly polluted. It can be seen from the average value of TDS $(1066.7 \mathrm{mg} / \mathrm{l})$, electrical conductivity $(1016.7 \mu \mathrm{m} / \mathrm{cm})$, and temperature $\left(24.96{ }^{\circ} \mathrm{C}\right.$ ) and concentrations of heavy metals $\mathrm{Cu}, \mathrm{Fe}$, and $\mathrm{Zn}$ which do not exceed quality standard based on Indonesian Minister of Environmental Regulation Number 5 of 2014. River water near the Andok River landfill is not polluted. It can be inferred from almost all measured parameters which are still below the quality standard based on Indonesian Government Regulation Number 82 of 2001. However, leachate from TPA probably affect Andok river water in which the value of all parameters for river water sample after passing TPA is higher than the value before passing the landfill. Water samples at monitoring wells have an average value of electrical conductivity of $300.5 \mu \mathrm{m} / \mathrm{cm}$, temperature of $24.67 \mathrm{OC}, \mathrm{pH}$ of 6.6 and TDS of $960 \mathrm{mg} / \mathrm{l}$. These values are almost the same as the value in the leachate samples. The concentration of heavy metals also exceeds the quality standard, and is higher than other samples. Thus, leachate has probably seeped into the soil layer.
\end{abstract}

Keywords : Sungai andok landfill, leachate, electric conductivity, Total Dissolve Solid (TDS), pH.

\title{
1. PENDAHULUAN
}

Meningkatnya laju pembangunan di semua sektor di daerah perkotaan telah memicu terjadinya peningkatan laju urbanisasi. Konsekuensi logis dari semua itu adalah meningkatnya aktivitas di perkotaan di berbagai sektor seperti perumahan, industri, dan perdagangan. Salah satu dampak dari aktivitas tersebut adalah limbah atau sampah (Badan Standardisasi Nasional, 2002). Sementara itu, perkembangan manajemen sampah tidak sebanding dengan laju timbunan sampah dan adanya kelemahan dari sistem pembuangan sampah yaitu tidak adanya sistem pengolahan sampah padat dan lindi. Selama ini lindi belum ditangani secara baik, cenderung dibiarkan begitu saja sehingga berpotensi besar mencemari lingkungan (Ali, 2011). Lindi dapat merembes ke dalam tanah, ataupun mengalir di permukaan tanah dan bermuara pada aliran air sungai. Apabila lindi masuk melalui tanah dan batuan sampai pada kedalaman yang lebih jauh maka akan menyebabkan polusi air tanah (Fitri, 2012).

Sampah yang tertimbun di lokasi TPA mengandung zat organik. Bila dibiarkan mengalir ke permukaan tanah atau air dapat menimbulkan efek negatif bagi lingkungan sekitar termasuk manusia. Lindi memiliki kandungan zat organik tinggi sehingga dapat menghabiskan kandungan oksigen dalam air dan akhirnya seluruh kehidupan dalam air yang tergantung pada keberadaan oksigen terlarut akan mati (Ali, 2011). Lindi juga mengandung logam berat. Konsentrasi logam berat yang berlebihan di dalam tubuh suatu organisme pada jangka waktu yang lama bisa merusak (Govind dan Madhuri, 2014). Hal ini berkaitan dengan sifat-sifat logam berat yaitu sulit terdegradasi, sehingga mudah terakumulasi dalam lingkungan perairan dan keberadaannya secara alami sulit terurai, dapat terakumulasi dalam organisme dan akan membahayakan kesehatan manusia. Efek toksik dari logam berat mampu menghalangi kerja enzim. Logam berat menjadi berbahaya karena sistem bioakumulasi, yaitu peningkatan konsentrasi unsur kimia di dalam tubuh mahluk hidup (Ismarti, 2011). 
Komposisi dan konsentrasi bahan pencemar di dalam lindi bervariasi antara TPA yang satu dengan TPA yang lain. Al-Wabel, dkk. (2011) yang melakukan penelitian mengenai karakteristik lindi di TPA di Kota Riyadh, Saudi Arabia menemukan bahwa lindi di lokasi tersebut mengandung COD, BOD, EC, TSS dengan konsentrasi yang tinggi. Selain itu, lindi di TPA Kota Riyadh mengandung Fe, Mn, Mo, Ni,Cr, Zn dan $\mathrm{Cu}$. Radzuan, dkk. (2005) yang melakukan penelitian untuk mengetahui karakteristik lindi di TPA Air Hitam di Puchong, Selangor menemukan bahwa lindi memiliki COD rendah dan konsentrasi logam berat $\mathrm{Fe}, \mathrm{Zn}, \mathrm{Pb}$, Ni yang relatif tinggi sedangkan $\mathrm{Mn}, \mathrm{Cd}, \mathrm{Cr}, \mathrm{Cu}$ yang ditemukan relatif rendah.

Pengendalian pencemaran yang efektif melalui perancangan TPA dan fasilitas manajemen lindi yang tepat memerlukan pemahaman kualitas lindi (Reinhart and Grosh, 1998). Pengetahuan atau data lindi juga dapat digunakan untuk memprediksi pola komposisi lindi di masa yang akan datang, khususnya untuk TPA dimana pengolahan lindi harus dirancang (Lo, 1996).

Lindi dari TPA Sungai Andok Kota Padang Panjang kemungkinan memiliki karakterstik tersendiri, untuk itu perlu dilakukan karakterisasi terhadap lindi di TPA tersebut. Tujuan dari penelitian ini adalah menentukan karakteristik lindi berdasarkan kandungan logam berat, temperatur, TDS dan konduktivitas listrik pada air permukaan yang berada disamping TPA Sungai Andok. Hasil penelitian tersebut diharapkan dapat mengetahui karakteristik lindi TPA Sungai Andok dan dapat dijadikan acuan dalam pengelolaannya.

\section{METODE PENELITIAN}

\subsection{Bahan dan Alat Penelitian}

Bahan yang digunakan dalam penelitian ini adalah sampel lindi dan air permukaan di sekitar TPA, kertas label, kertas saring, tisu,dan aquades. Alat yang digunakan adalah oven Memmert, gelas beaker, gelas ukur, timbangan moisture, conductivity meter, dan hot plate.

\subsection{Prosedur Penelitian}

Sampel diambil pada sembilan titik, yaitu 3 titik pada kolam lindi (sampel L1, L2, dan L3), satu di sumur pantau, dan 5 titik air permukaan di sungai yang berjarak sekitar 200 dari TPA Sungai Andok (sampel $\mathrm{H}_{\mathrm{I}} 1, \mathrm{H}_{\mathrm{I}} 2, \mathrm{H}_{\mathrm{U}} 2, \mathrm{H}_{\mathrm{U}} 3, \mathrm{H}_{\mathrm{I}} 1$, dan $\mathrm{H}_{\mathrm{I}} 2$ ). Jarak antar sampel pada sungai adalah $200 \mathrm{~m}$, sampel yang diambil dimasukkan ke botol $500 \mathrm{ml}$. Titik-titik pengambilan sampel diperlihatkan pada Gambar 1.

Pengukuran temperatur, $\mathrm{pH}$, dan nilai konduktivitas listrik diukur langsung di lapangan mengunakan $\mathrm{pH}$ meter dan conductivity meter. Pengukuran dan pengambilan sampel dilakukan dari jam 11.00 WIB sampai 14.00 WIB. Saat pengambilan sampel, temperatur udara adalah $26^{\circ} \mathrm{C}$ dan musim hujan. Pengukuran TDS dan kandungan logam berat dilakukan di Laboratorium. Nilai TDS diukur dengan langkah-langkah sebagai berikut: gelas beaker ukuran $50 \mathrm{ml}$ dibersihkan dan dikeringkan, kemudian dimasukkan ke dalam oven dan dipanaskan dengan suhu $105{ }^{\circ} \mathrm{C}$ selama 1 jam. Kemudian gelas beaker didinginkan dan ditimbang dengan menggunakan timbangan moisture sehingga didapatkan massa gelas beaker kosong (C). Pengukuran dilakukan sebanyak 3 kali. 


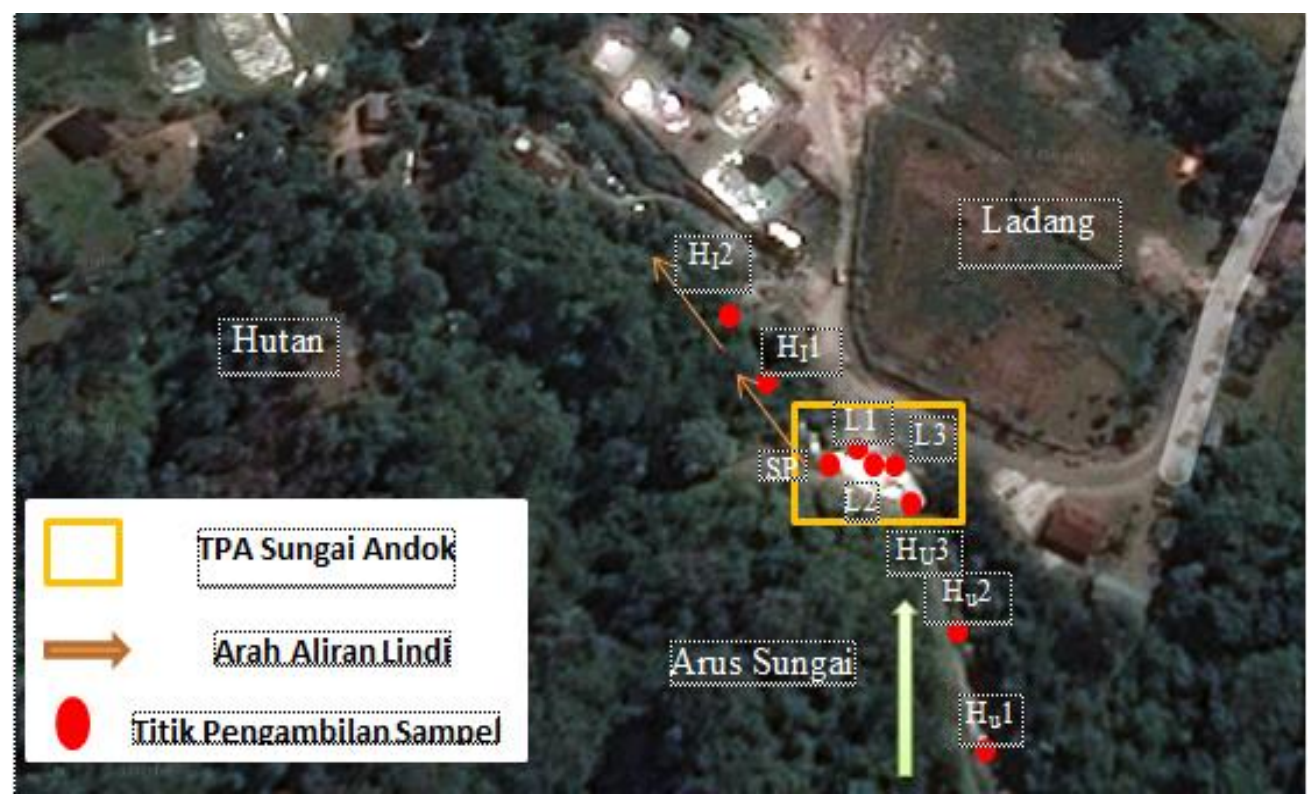

Gambar 1.Titik pengambilan sampel

Sampel air diaduk hingga homogen kemudian disaring hingga $25 \mathrm{ml}$ menggunakan kertas saring Whatman no. 41. Sampel tersebut dipanaskan di dalam gelas beaker menggunakan hot plate C-MAG HS dengan suhu $250{ }^{\circ} \mathrm{C}$ selama 1 jam sampai air di dalam gelas beaker habis. Sampel air dalam gelas beaker yang telah dipanaskan kemudian diuapkan menggunakan oven dengan suhu $105{ }^{\circ} \mathrm{C}$ selama 1 jam agar sampel benar-benar kering dari air dan hanya tersisa zat padat terlarut. Gelas beaker yang berisi zat padat terlarut didinginkan dan ditimbang dengan timbangan moisture sehingga didapatkan massa gelas beaker ditambah massa zat padat terlarut (B). Pengukuran massa ini dilakukan sebanyak 3 kali. Langkah 1 sampai 6 diulangi untuk semua sampel.Nilai TDS dihitung dengan Persamaan 1.

$$
T D S=\frac{B-C}{V} \times 1000
$$

dimana $B$ adalah massa gelas beaker ditambah massa zat padat terlarut $(\mathrm{mg}), C$ adalah massa gelas beaker kosong (mg), dan $V$ adalah volume sampel (ml).

\section{HASIL DAN DISKUSI}

Hasil pengukuran parameter berupa konduktivitas listrik, TDS, $\mathrm{pH}$, temperatur dan kandungan logam berat pada lindi dan air permukaan yang ada di TPA Sungai Andok dapat dilihat pada Tabel 1. Pada bagian ini akan dibahas nilai parameter terhadap standar baku mutu dan pengaruh lindi pada TPA terhadap air permukaan, yaitu air sungai dan air tanah. 
Tabel 1 Konduktivitas listrik, pH, TDS, temperatur dan kandungan logam berat lindi dan air permukaan di lokasi TPA Sungai Andok

\begin{tabular}{|c|c|c|c|c|c|c|c|c|}
\hline \multirow{2}{*}{$\begin{array}{c}\text { Nama } \\
\text { Sampel }\end{array}$} & \multicolumn{8}{|c|}{ Parameter ( satuan) } \\
\hline & $\operatorname{Suhu}\left({ }^{\circ} \mathrm{C}\right)$ & $\begin{array}{c}\text { TDS } \\
(\mathrm{mg} / \mathrm{l})\end{array}$ & $\begin{array}{c}\text { EC } \\
(\mu \mathrm{S} / \mathrm{cm})\end{array}$ & $\mathbf{p H}$ & $\begin{array}{c}\mathbf{P b} \\
(\mathbf{m g} / \mathbf{l})\end{array}$ & $\begin{array}{c}\mathrm{Zn} \\
(\mathrm{mg} / \mathrm{l})\end{array}$ & $\begin{array}{c}\mathrm{Cu} \\
(\mathrm{mg} / \mathrm{l})\end{array}$ & $\begin{array}{c}\mathbf{F e} \\
(\mathrm{mg} / \mathrm{l})\end{array}$ \\
\hline \multicolumn{9}{|c|}{ Sampelair sungai sebelum TPA } \\
\hline $\mathrm{H}_{\mathrm{U}} 1$ & 23,87 & 400 & 464 & 7,7 & 0,025 & 0,056 & 0,051 & 0,100 \\
\hline $\mathrm{H}_{\mathrm{U}} 2$ & 23,43 & 400 & 203 & 8,0 & 0,022 & 0,045 & 0,046 & 0,063 \\
\hline $\mathrm{H}_{\mathrm{U}} 3$ & 23,80 & 400 & 196 & 8,0 & 0,020 & 0,049 & 0,053 & 0,047 \\
\hline Rata-rata & 23,70 & 400 & 287,7 & 7,9 & 0,022 & 0,050 & 0,050 & 0,070 \\
\hline \multicolumn{9}{|c|}{ Sampel lindi pada TPA } \\
\hline L1 & 25,23 & 800 & 999 & 6,6 & 0,068 & 0,191 & 0,173 & 0,198 \\
\hline L2 & 24,83 & 1200 & 1114 & 6,6 & 0,110 & 0,318 & 0,204 & 0,302 \\
\hline L3 & 24,83 & 1200 & 937 & 6,7 & 0,124 & 0,358 & 0,257 & 0,343 \\
\hline Rata-rata & 24,96 & 1066,7 & 1016,7 & 6,6 & 0,101 & 0,289 & 0,211 & 0,281 \\
\hline \multicolumn{9}{|c|}{ Sampel air sumur pantau } \\
\hline SP & 24,67 & 960 & 367 & 6,3 & 0,144 & 0,408 & 0,295 & 0,410 \\
\hline \multicolumn{9}{|c|}{ Sampel air sungai setelah TPA } \\
\hline $\mathrm{H}_{\mathrm{I}} 1$ & 24,3 & 160 & 412 & 8,4 & 0,055 & 0,163 & 0,101 & 0,158 \\
\hline $\mathrm{H}_{\mathrm{I}} 2$ & 23,43 & 120 & 189 & 7,8 & 0,013 & 0,039 & 0,038 & 0,044 \\
\hline Rata-rata & 23,86 & 140 & 300,5 & 8,1 & 0,034 & 0,203 & 0,101 & 0,101 \\
\hline
\end{tabular}

\subsection{Nilai Konduktivitas Listrik}

Tabel.1 menunjukkan bahwa nilai konduktivitas listrik di lokasi TPA Sungai Andok berkisar antara 189 hingga $1114 \mu \mathrm{S} / \mathrm{cm}$. Nilai rata-rata pada sampel air sungai sebelum TPA adalah 287,67 $\mu \mathrm{S} / \mathrm{cm}$, pada lindi TPA sebesar 1066,7 $\mu \mathrm{S} / \mathrm{cm}$ dan air sungai setelah TPA 300,5 $\mu \mathrm{S} / \mathrm{cm}$. Nilai konduktivitas listrik lindi jauh lebih tinggi daripada sampel air lainnya. Hal ini karena lindi merupakan air yang terbentuk dari pembusukan sampah sehingga memiliki kandungan ion dan kation yang lebih tinggi. Dilihat dari nilai rata-rata konduktivitas listriknya, disimpulkan bahwa lindi mempengaruhi air sungai, dimana nilai konduktivitas listrik sampel air sungai setelah melewati TPA lebih besar daripada yang sebelum melewati TPA. Hal ini karena jarak TPA yang sangat dekat dengan sungai sehingga menyebabkan lindi dapat merembes ke sungai. Nilai konduktivitas listrik pada sampel air permukaan tidak melebihi nilai alaminya $(1500 \mu \mathrm{S} / \mathrm{cm})$ berdasarkan Peraturan Pemerintah Republik Indonesia (PP) Nomor 20 Tahun 1990. Sampel pada sumur pantau memiliki nilai rata-rata konduktivitas listrik sebesar $367 \mu \mathrm{S} / \mathrm{cm}$.

\subsection{Nilai pH}

Hasil pengukuran $\mathrm{pH}$ lindi dan air permukaan di lokasi penelitian yang ditampilkan pada Tabel1 menunjukkan bahwa nilai $\mathrm{pH}$ lindi bekisar antara 6,6 hingga 6,7 dan air permukaan berkisar antara 6,3 hingga 8,4. Nilai rata-rata $\mathrm{pH}$ untuk sampel air sungai sebelum TPA 7,9 dan setelah melewati TPA 8,1, sedangkan pada lindi adalah 6,6. Nilai pH lindi di TPA Sungai Andok berkisar antara 6 dan 9 dan masih berada pada rentang standar baku mutu yang ditetapkan Peraturan Menteri Lingkungan Hidup Republik Indonesia (PERMEN LH) Nomor 5 Tahun 2014. Begitu pula dengan air permukaan, nilainya masih dalam rentang baku mutu $\mathrm{pH}$ air sungai berdasarkan Peraturan Pemerintah Republik Indonesia PP No. 82 Tahun 2001 yaitu antara 6,0 dan 9,0. Nilai tersebut menunjukkan $\mathrm{pH}$ air sungai yang berada sekitar $200 \mathrm{~m}$ dari TPA Sungai Andok masih dalam batas yang diperbolehkan dalam penggunaannya. 


\subsection{Temperatur}

Hasil pengukuran menunjukkan bahwa fluktuasi temperatur sangat rendah, berkisar antara $23,43-25,23{ }^{\circ} \mathrm{C}$ (Tabel 1). Temperatur lindi paling tinggi adalah pada titik L1, yaitu lindi sebelum memasuki kolam dengan temperatur $25,23{ }^{\circ} \mathrm{C}$, kemudian sampel L2 dan L3 dengan temperatur $24,83{ }^{\circ} \mathrm{C}$ dan sampel SP dengan temperatur $24,67{ }^{\circ} \mathrm{C}$. Temperatur rata-rata sampel air permukaan tidak jauh berbeda antara sampel air setelah melewati TPA dengan sampel air sebelum TPA.Temperatur sampel air sumur pantau tidak jauh berbeda dengan temperatur lindi. Hal ini bisa disebabkan oleh pengaruh rembesan lindi. Apabila dibandingkan dengan baku mutu air limbah berdasarkan PERMEN LH Nomor 5 Tahun 2014, temperatur lindi masih di bawah baku mutu. Berdasarkan baku mutu air kelas 1 (PP No 82 Tahun 2001), temperatur air sumur pantau dan air sungai masih berada pada kisaran temperatur yang diperbolehkan dan tergolong normal yaitu $25 \pm 3^{0} \mathrm{C}$.

\subsection{Total Dissolved Solid}

Tabel 1 menunjukkan nilai padatan terlarut atau total dissolved solid (TDS) di lokasi TPA Sungai Andok bekisar dari $120 \mathrm{mg} / \mathrm{l}$ sampai $1200 \mathrm{mg} / \mathrm{l}$. Nilai rata-rata TDS sampel air sungai sebelum TPA sebesar $400 \mathrm{mg} / \mathrm{l}$, pada lindi TPA adalah $1066,7 \mathrm{mg} / \mathrm{l}$ dan setelah melewati TPA sebesar $140 \mathrm{mg} / \mathrm{l}$. Nilai TDS untuk sampel air sungai setelah melewati TPA lebih rendah dibandingkan dengan sebelum melewati TPA. Hal ini kemungkinan disebabkan adanya sungai lain yang bermuara pada titik pengambilan sampel di hilir sungai. Sampel dari sumur pantau memiliki nilai TDS tidak jauh berbeda dengan lindi. Dengan demikian, dapat dilihat bahwa lindi mempengaruhi air tanah disekitar TPA karena tidak adanya pembatas. Nilai TDS lindi tidak melebihi baku mutu yaitu $2000 \mathrm{mg} / \mathrm{l}$ menurut PERMEN LH Nomor 5 Tahun 2014. Nilai TDS air permukaan yang tidak melebihi baku mutu berdasarkan PP Nomor 82 Tahun 2001 yaitu 1000 mg/l mengindikasikan bahwa air sungai dapat digunakan untuk semua peruntukan.

\subsection{Kandungan Logam Berat Besi}

Kandungan logam berat besi (Fe) di lokasi sekitar TPA Sungai Andok berkisar dari 0,044 $\mathrm{mg} / \mathrm{l} \mathrm{sampai} 0,410 \mathrm{mg} / \mathrm{l}$. Nilai rata-rata Fe pada lindi adalah $0,281 \mathrm{mg} / \mathrm{l}$, pada air sungai sebelum melewati TPA sebesar $0,070 \mathrm{mg} / \mathrm{l}$ dan setelah melewati TPA sebesar $0,101 \mathrm{mg} / \mathrm{l}$ (Tabel 1). Kandungan Fe pada sampel air sungai setelah TPA lebih tinggi dibandingkan dengan sebelum melewati TPA. Kandungan logam berat Fe pada sampel sumur pantau lebih tinggi daripada sampel lindi. Konsentrasi Fe dalam lindi secara umum memiliki nilai lebih kecil daripada standar baku mutu air limbah yang ditetapkan PERMEN LH Nomor 5 Tahun 2014 yaitu 5 mg/l dan PP Nomor 82 Tahun 2001 sebesar 0,3 mg/l. Berdasarkan nilai konsentrasi Fe tersebut, lindi boleh dialirkan ke sungai atau badan air penerima. Konsentrasi Fe sampel air sungai juga memiliki kadar di bawah baku mutu sehingga air sungai tersebut dapat digunakan untuk keperluan berbagai aktivitas.

\subsection{Kandungan Logam Berat Timbal}

Tabel 1 menunjukkan nilai rata-rata logam berat timbal $(\mathrm{Pb})$ pada lindi adalah 0,101 mg/l. Nilai tersebut sedikit melebihi batas baku mutu berdasarkan PP Nomor 5 Tahun 2014 yakni sebesar $0,1 \mathrm{mg} / \mathrm{l}$. Nilai rata-rata konsentrasi $\mathrm{Pb}$ pada sampel air sungai sebelum melewati TPA yaitu $0,022 \mathrm{mg} / \mathrm{l}$ dan setelah melewati TPA sebesar $0,034 \mathrm{mg} / \mathrm{l}$. Pada sumur pantau kadar $\mathrm{Pb}$ yang diperoleh adalah $0,144 \mathrm{mg} / \mathrm{l}$. Berdasarkan PP Nomor 82 
Tahun 2001 kadar Pb pada sampel air permukaan masih di bawah standar baku mutu, kecuali pada sampel sumur pantau.

\subsection{Kandungan Logam Berat Tembaga}

Konsentrasi logam tembaga $(\mathrm{Cu})$ pada seluruh sampel berkisar antara 0,039 sampai 0,295 $\mathrm{mg} / \mathrm{l}$. Konsentrasi rata-rata $\mathrm{Cu}$ pada lindi adalah $0,211 \mathrm{mg} / \mathrm{l}$, pada sampel air sungai sebelum TPA sebesar $0,050 \mathrm{mg} / \mathrm{l}$ dan setelah melewati TPA $0,0695 \mathrm{mg} / \mathrm{l}$, dan pada sumur pantau sebesar 0,211 mg/l (Tabel 1). Sampel air sungai setelah TPA memiliki konsentrasi $\mathrm{Cu}$ lebih tinggi daripada daerah sebelum melewati TPA. Sumur pantau memiliki nilai kadar $\mathrm{Cu}$ lebih tinggi daripada lindi. Berdasarkan PERMEN LH Nomor 5 Tahun 2014 konsentrasi $\mathrm{Cu}$ pada lindi belum melebihi baku mutu. Sedangkan untuk air permukaan, berdasarkan PP Nomor 82 Tahun 2001, nilainya sedikit melebihi baku mutu yaitu 0,02 $\mathrm{mg} / \mathrm{l}$.

\subsection{Kandungan Logam Berat Seng}

Tabel 1 menunjukkan konsentrasi logam berat seng $(\mathrm{Zn})$ pada sampel berkisar antara $0,039 \mathrm{mg} / \mathrm{l}$ sampai $0,408 \mathrm{mg} / \mathrm{l}$. Konsentrasi rata-rata $\mathrm{Zn}$ pada sampel lindi adalah 0,289 $\mathrm{mg} / \mathrm{l}$, pada sampel air sungai sebelum TPA sebesar $0,050 \mathrm{mg} / \mathrm{l}$ dan setelah melewati TPA 0,0695. Berdasarkan PERMEN LH Nomor 5 Tahun /2014, konsentrasi Zn pada lindi tidak melebihi baku mutu yaitu $5 \mathrm{mg} / \mathrm{l}$. Berdasarkan PP Nomor 82 Tahun 2001 konsentrasi Zn pada air permukaan tidak melebihi baku mutu. Konsentrasi Zn tertinggi pada sumur pantau, diikuti lindi. Konsentrasi Zn pada sampel air hulu sungai nilainya cenderung konstan, kemudian pada hilir sungai nilainya mengalami kenaikan dan turun kembali pada titik terakhir pengambilan sampel. Konsentrasi $\mathrm{Zn}$ pada air sungai mengalami kenaikan setelah melewati TPA dibanding sebelum melewati TPA. Konsentrasi $\mathrm{Zn}$ pada sumur pantau lebih tinggi daripada pada lindi. Jadi, dapat dilihat adanya pengaruh lindi pada air permukaan di sekitar TPA Sungai Andok.

\section{KESIMPULAN}

Secara umum lindi di sekitar TPA Sungai Andok tidak mengalami pencemaran tinggi. Hal ini terlihat darinilai rata-rata TDS $(1066,7 \mathrm{mg} / \mathrm{l})$, konduktivitas listrik $(1016,7$ $\mu \mathrm{m} / \mathrm{cm})$, dantemperatur $\left(24,96{ }^{\circ} \mathrm{C}\right)$ dan konsentrasi logam berat $\mathrm{Cu}, \mathrm{Fe}$, dan $\mathrm{Zn}$ yang tidak melebihi standar baku mutu berdasarkan PERMEN LH Nomor 5 Tahun 2014. Kondisi lindi yang tidak mengalami pencemaran tinggi menyebabkan air sungai yang berada dekat TPA masih belum tercemar. Semua parameter yang diukur masih di bawah baku mutu berdasarkan PP Nomor 82 Tahun 2001. Namun, lindi dari TPA diduga mempengaruhi air sungai Andok dimana nilai semua parameter pada sampel air pada bagian sungai setelah melewati TPA lebih tinggi daripada nilai sebelum melewati TPA. Hal ini juga terlihat dari parameter yang terukur dari sumur pantau.Sampel air pada sumur pantau memiliki nilai rata-rata konduktivitas listrik sebesar $300,5 \mu \mathrm{m} / \mathrm{cm}$, temperatur sebesar $24,67{ }^{\circ} \mathrm{C}, \mathrm{pH}$ adalah 6,6 dan TDS sebesar $960 \mathrm{mg} / \mathrm{l}$. Nilai-nilai tersebut hampir sama dengan nilai pada sampel lindi. Konsentrasi logam berat yang didapat juga melebihi baku mutu, dan lebih tinggi daripada sampel lainnya. Berdasarkan hasil ini diperkirakan lindi telah merembes ke dalam lapisan tanah. 


\section{UCAPAN TERIMA KASIH}

Ucapan terimakasih kami sampaikan kepada petugas di TPA Sungai Andok, Padang Panjang atas akses dan informasi yang telah diberikan dan bantuannya dalam pengambilan sampel.

\section{DAFTAR PUSTAKA}

1. Ali, M., 2011, Rembesan Air Lindi (Leachate) Dampak pada Tanaman dan Kesehatan, UPN Press, Surabaya.

2. Al-Wabel, M. I., Al Yehya, W. I., Al-Farraj, S. E, dan El-Maghraby, 2011, Characteristic of Landfill Leachates and Bio-Solids of Municipal Solid Waste (MSW) in Riyadh City Saudi Arabia, Journal of the Saudi Society of Agricultural Sciences, Vol. 10, Hal. 65-70.

3. Badan Standardisasi Nasional, SNI 19 - 2454 - 2002, Tata Cara Pengelolaan Teknis Sampah Perkotaan, Jakarta, 2002.

4. Fitri,R.,2012, Kajian Air Lindi di Tempat Pembuangan Akhir Terjun Menggunakan Metode Thornwaite,Tesis, PPs USU, Medan.

5. Ismiati, 2011, Pencemaran Logam Berat Di Perairan Dan Efeknya Pada Kesehatan Manusia, http://repository usu.ac.id, diakses Mei 2017.

6. Lo, I. M. C., 1996, Characteristic and Treatment of Leachate from Domestis Landfill, Environment International, 22:433-442

7. Radzuan, N.Z.M., 2005, Characteristic of Leachate at the Air Hitam Sanitary Landfill in Puchong, Selangor, Geological Society of Malaysia Bulletin 51, June 2005 p.41-46.

8. Reinhart, D.R. \& Grosh, C.J., 1998, Analysis of Florida MSW Landfill Leachate Quality. Final Report, University of Central Florida.

9. Peraturan Menteri Lingkungan Hidup Republik Indonesia (PERMEN LH) Nomor 5 Tahun 2014 Tentang Baku Mutu Air Limbah.

10. Peraturan Pemerintah Republik Indonesia (PP) Nomor 20 Tahun 1990 Tentang Pengendalian Pencemaran Air.

11. Peraturan Pemerintah Republik Indonesia (PP) Nomor 82 Tahun 2001 Tentang Pengelolaan Kualitas Air dan Pengendalian Pencemaran Air. 